\title{
Effect of Postoperative Exercise Program on Knee Physical Function Among High Tibial Osteotomy Patients
}

\author{
Hesham Abd El-Rahim Elkady ${ }^{1}$, Nagwa Mohamed Ahmed ${ }^{2}$, Shimaa Hussien ${ }^{2,}$, Marwa Ali ${ }^{2}$ \\ ${ }^{1}$ Orthopedic Surgery, Faculty of Medicine, Assiut University, Assiut, Egypt \\ ${ }^{2}$ Medical-Surgical Nursing, Faculty of Nursing, Assiut University, Assiut, Egypt
}

Email address:

shimaalshazly@yahoo.com (S. Hussien)

*Corresponding author

\section{To cite this article:}

Hesham Abd El-Rahim Elkady, Nagwa Mohamed Ahmed, Shimaa Hussien, Marwa Ali. Effect of Postoperative Exercise Program on Knee Physical Function Among High Tibial Osteotomy Patients. American Journal of Nursing Science. Vol. 9, No. 4, 2020, pp. 258-266. doi: 10.11648/j.ajns.20200904.27

Received: June 21, 2020; Accepted: July 7, 2020; Published: July 17, 2020

\begin{abstract}
Background: High tibial osteotomy is preferential treatment for patients with knee osteoarthritis. Strengthening exercise program helps post (HTO) patients achieve greater functioning during sport, recreation, and activities of daily living after surgery. Objective: To examine the effect of postoperative exercise program on knee physical function among high tibial osteotomy patients. Method: Design: quasi experimental research design. Setting: Department of Orthopedic Surgery and orthopedic Outpatient Clinic at Assiut University Hospital. Sample: A purposive sample of 60 adult patients undergoing high tibial osteotomy were included in our study. Method: Knee Outcome Survey Activities of Daily Living Scale and Lysholm knee scoring scale were used. Results: A highly statistically significant improvement of knee Function score and Lysholm knee score $(<0.001 * *)$ among patients with high tibial osteotomy. Conclusion: Application of exercise program had a statistically significant effect on improvement physical function of knee among the study group than among the control group. Recommendations: Successful postoperative exercises should be practiced for each patient undergoing high tibial osteotomy in order to improving physical function of the knee.
\end{abstract}

Keywords: Exercise Program, Knee Physical Function, High Tibial Osteotomy

\section{Introduction}

High tibial osteotomy is operation performed to alleviate pressure on the damaged site of an arthritic knee. It's normally disbursed under arthritic conditions affecting only one side of the knee. The goal is to wish pressure off the affected area with healthy cartilage and a distinct side of the knee. During the surgery, the surgeon will remove or add a wedge of bone either below or above the joint, in line with the situation of arthritic damage [1]. Candidates for HTOs are patients who have pain and instability the situation varus ankle malalignment. Other indications additionally to presence of varus knee are meniscal transplantation after total medial meniscectomy, isolated chondral defect within the medial compartment of a varus knee, secondary degenerative joint disease in an exceedingly varus knee with medial joint line pain, and ligamentous instability with varus thrust within which correction of the varus deformity unloads the reconstructed ligament while it heals [2] Related x-rays begin with four primary views, including antero posterior and lateral knee views, patella femoral joint axial view and weight alignment view, all of which display lower extremities. On anterio posterior radiograph, the angle of the tibia bone varus is about and a good predictive factor after osteotomy is tibia bone varus $>5$ The lateral $x$-ray tests the peak of the patella by insall-index [3].

Lateral wedge closing osteotomy, Medial open wedge osteotomy and Dome osteotomy are three kinds of osteotomy. The osteotomy of the lateral wedge is the primary treatment and is more common to surgeons. Drawbacks include concomitant fibular osteotomy or release of the proximal tibio fibular joint, the possibility of peroneal nerve damage, the need for two bone cuts, the need to correct malalignment in one plane (frontal), shortening of the hip, loss of bone stock and more complicated transition to arthroplastic muscle 
detachment [4]

Lateral closing wedge osteotomy is ideally suited for patients with heavy smoking, diabetes or excessive use of non-union-related steroids. In addition, the operation should be carried out when there is patellar infera, the patient does not want bone grafting or anterior cruciate ligament repair may be done in addition [5].

Medial open wedge osteotomy recently became more common. The advantages are the power to correct alignment in two planes (coronal and sagittal), no need for fibular osteotomy, low risk of peroneal nerve injury, no shortening of the limbs, use of one cut without muscle detachment, no loss of bone, easier conversion to arthroplasty and also the ability to regulate the number of correction during surgery. the requirement for bone grafting and also the risk of delayed union or nonunion are drawbacks. Medium opening wedge osteotomy could also be more practical than closing wedge. HTO in knees with a discrepancy of $\sim 2 \mathrm{~mm}$ leg length, a mix of posterior cruciate ligament injury, Patella, or medial collateral laxity [6].

Other HTO techniques include dome osteotomy. Dome osteotomy or progressive callus distraction is indicated when an oversized degree of correction involving $18-20 \mathrm{~mm}$ opening or closing or $\geq 20^{\circ}$ angular correction is critical for traumatic varus deformity or Blount disease. Dome osteotomy is also a procedure using an inverse U-shaped proximal tibial bone cut and a metal plate for fixation or an external fixator for progressive correction. This procedure is useful for achieving correction with none changes within the patellar height [4].

Post-operative complications could also be major or minor. Major complications include major nerve injury, Compartment syndrome, Deep infection, Nonunion, Fixation failure, Deformity, Instability, Tibial plateau fracture while minor complications include nerve injury, Superficial wound infection, Flexion contracture, Skin irritation and Fibular nonunion [7].

Postoperative exercise aims are minimizing joint pain, swelling, and hemarthrosis; restoring natural knee flexion and extension; preventing osteotomy from displacement; resume a traditional gait pattern and neuromuscular stability For ambulation; restore muscle strength lower extremity, proprioception, balance and coordination for desired activities; and achieve optimum functional outcome approved orthopedic and patient goals [8].

Early joint exercises should be initiated. Partial weight bearing exercises should be performed with the knee protected during a hinged brace. Weight bearing should be increased progressively between 6 to 12 weeks with the brace removed. Maintenance of correction and bone union should be assessed through radiography on a routine and thus the lower limb alignment on full length radiographs of the lower extremity at 6 months postoperatively. A hinged brace should be worn for 6 postoperative weeks and weight bearing is started increasing depending on the bone union status [9].

Significance of the Study

High tibial osteotomy is commonest surgical intervention for treating knee mal alignment related to pain in young and active patients. Post-operative exercise is extremely important to keep up full range of motion adequate the other knee, minimal joint swelling, adequate strength and neuromuscular control, and a positive state of mind. All of those factors facilitate optimal post-operative recovery. During the year 2019, 96 HTO surgery were performed, in step with medical records at Assiut University Hospital.

\section{Aim of the Study}

The aim of the study was to examine the effect of postoperative exercise program on knee physical function among high tibial osteotomy patients

1Hypothesis:

To achieve the aim of this study, the following research hypothesis was formulated:

- Post participation in the exercise program, the study subjects will show higher improvement in physical knee function than control group.

\section{Subjects and Methods}

\subsection{Research Design}

Quasi experimental research design was utilized during this study. Which is used to determines whether exercise program has the intended effect on target population.

\subsection{Setting}

The study was conducted in department of orthopedic surgery and outpatient orthopedic clinic at Assiut University Hospital.

\subsection{Subjects}

A purposive sample of 60 adult patients (male and female), undergoing high tibial osteotomy surgery, age ranged from 18 to 60 , and both male and female were included in this study. Patients were equally divided on random basis into two equal groups (study and control) 30 patients each. The study group received the exercise program while the control group received the routine care. The sample was determined by using power analysis according to the patients flow with precision levels $5 \%$ at confidence level $95 \%$ and $\mathrm{p}<.05$.

\subsection{Tools: Data of This Study Was Collected Using the Following Tools}

Tool I: Structured Interview questionnaire sheet: It was designed by the researchers based on literature review, it included three parts:

Part (1): Demographic data: Age, gender, marital status, qualification, occupation, height, weight and body mass index.

Part (2): Medical data: Such as data of surgery, causes of surgery, kind of high tibial osteotomy surgery, main 
complain, diagnostic tools, chronic disease and medication used.

Part (3): patients' activity and environment; work requirements, residence level, What to use to reach the upper floors and types of toilet

Tool II: Measures of knee physical function through the following 2 scales:

1) Knee Outcome Survey Activities of Daily Living Scale (ADLS) [10]

ADLS is a 14-component scale that inquires patients about how knee symptoms affect their ability On the performance of general daily activities (6 items) as well as how they affect knees provided they are able to perform specific job tasks ( 8 items). Each item scored 0-5 with 5 indicating "no difficulty" and 0 representing "unable to implement". The highest possible score is summed up by 70. And scores of all elements, divided by 70, are then multiplied by 100 to give an overall ADLS percent rating. Higher percentages reflect higher levels of functional ability. This scope would be appropriate for patients who either do not participate in sports or recreational activities or for those who have not yet provided implementation of these activities.

2) Lysholm knee scoring scale: [11]

The Lysholm scale consists of 8 items to measure: pain (25 points), instability (25 points), locking (15 points), swelling (10 points), limping (5 points), stair climbing (10 points), squatting ( 5 points), and the need for support (5 points). Each question response was set to an arbitrary degree on an increasing scale. The overall score is the sum of all responses to the eight questions, and may range from 0-100. Higher scores indicate better results with fewer symptoms or disabilities.

\subsection{Nursing Exercise Booklet}

It developed by researchers based on the content of the best practice statement for postoperative exercises (it included types of postoperative exercises that can be done, frequency, duration and precautions that can be taken) for completion and application by the researcher.

\subsection{Ethical Considerations}

A study by the ethics committee and faculty and hospital authorities of the Department of Orthopedics and Outpatient Clinics of the Bones confirmed. Before the initial interview, the researchers presented themselves to patients who met the inclusion criteria. Each patient was fully informed of the purpose and nature of the study, and then obtained consent to participate The researchers emphasized that participation in this study is completely voluntary and withdrawal from the study will not affect the care provided; and confirmed anonymity and confidentiality through data encryption

\subsection{Content Validity}

It established by a panel of five experts (three experts from
Medical Surgical Nursing staff and two orthopedic Surgery staff) who reviewed the tools for clarity, relevance, comprehensively, understanding and applicability. No modifications were required. Test reliability of the proposed tools was ascertained with Cronbach's alpha $=0.82$.

Pilot Study:

A pilot study was conducted during January 2019 , on $10 \%$ of patients who were included within the research to look at clarity and feasibility of the used tool; those patients were included within the main study as there was no modification needed within the study tool.

\subsection{Procedure}

The study was performed through three phases:

1) Preparatory Phase:

Tools and exercise program development: A review of current and past, local and international related literature. Books, journals, periodicals and magazines were used in various aspects.

2) Implementation Phase:

At initial interview the researcher introduced herself to initiate line of communication, explain the nature \& purpose of the study and base line data was established using the Structured Interview Questionnaire sheet (tool I).

The researcher meets each patient individually and describes the study and its goals to the patient

For the study group; after filling the Structured Interview Questionnaire sheet, the researcher demonstrate to the patient the postoperative exercise in two sessions, the duration of each session was about half hour, including 10 minutes for discussion and feedback in the following sequence:

The researcher in the first session explain to the patient simple information about anatomical overview of the knee joint and function, indication and description of surgery, post-operative complication.

Second session was specified exercises which were demonstrated by the researcher to the patient.

Copies of the postoperative exercise booklets were provided for every patient within the study group.

For control group they receive routine hospital postoperative instructions and physiotherapy.

The time and place for follow up were arranged with the patients after four months within the out patients clinic of orthopaedic at Assiut University Hospital.

This study was carried out through the period from February 2019 to July 2019 at morning shift.

3) Evaluation phase:

Upon the patient's discharge from the hospital, the researcher approached the patient for follow-up in an out patients clinic of orthopaedic (4 months after the surgery) to re-evaluate the effectiveness of the exercise program through reassessment of subjects' knee physical function using (Tool II) for the studied patients.

Statistical analysis:

The data were verified for normality using the AndersonDarling test and for homogeneity variances prior to further statistical analysis. Categorical variables were described by 
number and percent $(\mathrm{N}, \%)$, where continuous variables described by mean and standard deviation (Mean, SD). Chisquare test and fisher exact test accustomed to compare between categorical variables where compare between continuous variables by t-test. A double-tailed $\mathrm{p}<005$ was considered statistically significance. All research was performed using the IBM SPSS 20.0 program.

\section{Results}

Table 1 Shows the mean of age $42.53 \pm 9.44$ years in study group and $43.73 \pm 10.42$ in control group, more than half of patients in the control group were males, while more than half of patients in the study group were females, the majority of patients in both control and study groups were married. More than two fifth in both study and control groups had obtained a secondary school education, while, More than two fifth of the studied patients were employed and more than half of the studied patients were obese $(53.3 \%$ \& $66.7 \%$ respectively). Finally, there were no statistically significant differences between two groups regarding socio-demographic data.

Table 1. Frequency distribution of demographic characteristics of the studied patients $(n=60)$.

\begin{tabular}{|c|c|c|c|c|c|}
\hline \multirow{2}{*}{ Characteristics } & \multicolumn{2}{|c|}{ Study $(n=30)$} & \multicolumn{2}{|c|}{ Control $(n=30)$} & \multirow{2}{*}{ P. value } \\
\hline & No & $\%$ & No & $\%$ & \\
\hline \multicolumn{6}{|l|}{ Age group } \\
\hline Less than 30 years & 3 & 10.0 & 4 & 13.3 & \multirow{3}{*}{0.357} \\
\hline From $31-40$ years & 11 & 36.7 & 6 & 20.0 & \\
\hline more than 40 years & 16 & 53.3 & 20 & 66.7 & \\
\hline Mean & \multicolumn{2}{|c|}{$42.53 \pm 9.44$} & \multicolumn{2}{|c|}{$43.73 \pm 10.42$} & 0.642 \\
\hline \multicolumn{6}{|l|}{ Gender } \\
\hline Female & 12 & 40.0 & 18 & 60.0 & 0.121 \\
\hline \multicolumn{6}{|l|}{ Marital status } \\
\hline Single & - & - & 2 & 6.7 & \multirow{3}{*}{0.117} \\
\hline Married & 30 & 100.0 & 26 & 86.7 & \\
\hline Divorced & - & - & 2 & 6.7 & \\
\hline \multicolumn{6}{|l|}{ Level of education } \\
\hline High education & 4 & 13.3 & 4 & 13.3 & \multirow{2}{*}{0.094} \\
\hline Illiterate & 10 & 33.3 & 4 & 13.3 & \\
\hline \multicolumn{6}{|l|}{ Occupation } \\
\hline Employee & 16 & 53.3 & 12 & 40.0 & \multirow{4}{*}{0.272} \\
\hline Student & - & - & 2 & 6.7 & \\
\hline Farmer & 4 & 13.3 & 2 & 6.7 & \\
\hline House wife & 10 & 33.3 & 14 & 46.7 & \\
\hline \multicolumn{6}{|l|}{ Body mass index } \\
\hline Normal weight & 3 & 10.0 & 2 & 6.7 & \multirow{3}{*}{0.572} \\
\hline Overweight & 11 & 36.7 & 8 & 26.7 & \\
\hline Obese & 16 & 53.3 & 20 & 66.7 & \\
\hline Mean+SD & 30.1 & & 32.2 & & 0.086 \\
\hline
\end{tabular}

Table 2. Percentage distribution of medical data for both study \& control groups.

\begin{tabular}{|c|c|c|c|c|c|}
\hline \multirow{2}{*}{ Medical data } & \multicolumn{2}{|c|}{ Study $(n=30)$} & \multicolumn{2}{|c|}{ Control $(n=30)$} & \multirow{2}{*}{ P. value } \\
\hline & No & $\%$ & No & $\%$ & \\
\hline \multicolumn{5}{|l|}{ Cause of surgery: } & \multirow{7}{*}{$<0.001 * *$} \\
\hline Accident & 4 & 13.3 & - & - & \\
\hline $\mathrm{ACL}$ & 1 & 3.3 & - & 6.7 & \\
\hline Falling & 10 & 33.3 & 2 & - & \\
\hline Fracture & 1 & 3.3 & - & & \\
\hline Knee stiffness & 9 & 30.0 & - & - & \\
\hline $\mathrm{OA}$ & 4 & 13.3 & 28 & 93.3 & \\
\hline \multicolumn{6}{|l|}{ Affected side } \\
\hline Right & 12 & 40.0 & 28 & 93.3 & \multirow{2}{*}{$<0.001 * *$} \\
\hline Left & 18 & 60.0 & 2 & 6.7 & \\
\hline \multicolumn{5}{|l|}{ Type of high tibial osteotomy surgery } & \multirow{4}{*}{$0.028 *$} \\
\hline Medial open wedge osteotomy & 11 & 36.7 & 14 & 46.7 & \\
\hline Dome Osteotomy & 6 & 20.0 & 12 & 40.0 & \\
\hline Current patients complain & & & & & \\
\hline
\end{tabular}




\begin{tabular}{|c|c|c|c|c|c|}
\hline \multirow{2}{*}{ Medical data } & \multicolumn{2}{|c|}{ Study $(n=30)$} & \multicolumn{2}{|c|}{ Control $(n=30)$} & \multirow{2}{*}{ P. value } \\
\hline & No & $\%$ & No & $\%$ & \\
\hline Pain & 23 & 76.7 & 30 & 100.0 & $0.005 * *$ \\
\hline Weakness & 20 & 66.7 & 6 & 20.0 & $<0.001^{* *}$ \\
\hline Crepitus or crackling sensation when moving leg & 21 & 70.0 & 2 & 6.7 & $<0.001 * *$ \\
\hline Swilling & 13 & 43.3 & 8 & 26.7 & 0.176 \\
\hline \multicolumn{6}{|l|}{ Diagnosis Methods } \\
\hline Medical History and Physical Examination & 2 & 6.7 & 6 & 20.0 & \multirow{3}{*}{0.219} \\
\hline X-rays & 15 & 50.0 & 10 & 33.3 & \\
\hline Magnetic resonance imaging (MRI) or ultrasound & 13 & 43.3 & 14 & 46.7 & \\
\hline \multicolumn{6}{|l|}{ Medical history } \\
\hline Diabetes mellitus & 1 & 3.3 & - & - & 0.313 \\
\hline Hypertension & 3 & 10.0 & - & - & 0.076 \\
\hline Cardiovascular disease & 1 & 3.3 & - & - & 0.313 \\
\hline Previous knee surgery & 11 & 36.7 & 4 & 13.3 & $0.037 *$ \\
\hline
\end{tabular}

Table 2 Reveals that the highest percent of study group had high tibial osteotomy related to falling $(33.3 \%)$ while in the control group (93.3\%) was occur due to OA. The most affected side in study group was the left side (60.0) while in the control group was the right side (93.3). In relation to type of operation, this table shows that the highest percent of patients in the study group underwent lateral closing wedge osteotomy $(43.3 \%)$, while $(46.7 \%)$ of the control group has been done medial open wedge osteotomy. Concerning main complain, data showed that, three quarter of patients in the study group (76.7\%) complained from pain, while (100.0\%) experienced pain in the control group.

Table 3. Percentage distribution of patients' activity and environment for both study \& control groups.

\begin{tabular}{|c|c|c|c|c|c|}
\hline \multirow{2}{*}{ patients' activity and environment } & \multicolumn{2}{|c|}{ Study $(n=30)$} & \multicolumn{2}{|c|}{ Control $(=30)$} & \multirow{2}{*}{ P. value } \\
\hline & No & $\%$ & No & $\%$ & \\
\hline \multicolumn{6}{|l|}{ Work requirements: } \\
\hline Long standing & 16 & 53.3 & 24 & 80.0 & $0.028^{*}$ \\
\hline Sitting & 14 & 46.7 & - & - & $<0.001^{* *}$ \\
\hline Carrying heavy objects & 19 & 63.3 & 18 & 60.0 & 0.791 \\
\hline Bend your knee & 12 & 40.0 & 18 & 60.0 & 0.121 \\
\hline Use of bicycle & 2 & 6.7 & 10 & 33.3 & $0.010^{*}$ \\
\hline \multicolumn{6}{|l|}{ Residence level } \\
\hline 1 & 12 & 40.0 & 6 & 20.0 & \multirow{4}{*}{0.060} \\
\hline 2 & 11 & 36.7 & 12 & 40.0 & \\
\hline 3 & 4 & 13.3 & 12 & 40.0 & \\
\hline 4 & 1 & 3.3 & - & - & \\
\hline \multicolumn{6}{|l|}{ What to use to reach the upper floors } \\
\hline Stairs & 29 & 96.7 & 28 & 93.3 & \multirow{2}{*}{0.554} \\
\hline electrical elevator & 1 & 3.3 & 2 & 6.7 & \\
\hline \multicolumn{6}{|l|}{ Type of toilet } \\
\hline squatting pan & 11 & 36.7 & 24 & 80.0 & \multirow{2}{*}{$0.001 * *$} \\
\hline water closet toilet & 19 & 63.3 & 6 & 20.0 & \\
\hline
\end{tabular}

Table 3. Illustrates that more than three quarter of study patients were using stairs to go up and do, while more than half of patients in the control group were carrying heavy objects and bending his knee. As regarding the residence level, about two fifth of patients in the study sample lived in the first floor, while the majority in the control sample lived in the second and third level. The vast majority of patients in both groups used stairs to climb to the upper floors. According to the type of toilet $(63.3 \%)$ of patients in study sample they were using water closet toilet, while $(80.0 \%)$ of patients in the control group they were using squatting pan.

Table 4. The mean score of knee Function scale and Lysholm knee scale of study \& control group patients after Application exercise program.

\begin{tabular}{llllll}
\hline \multirow{2}{*}{ Knee physical function } & Before & & \multicolumn{3}{c}{ After } \\
\cline { 2 - 6 } & Control & study & P. value & Control & Study \\
\hline Activities of Daily Living Scale & $16.33 \pm 10.98$ & $16.89 \pm 18.36$ & 0.887 & $58.44 \pm 8.83$ & $86.89 \pm 12.28$ \\
Lysholm knee scoring scale & $25.4 \pm 6.79$ & $25.9 \pm 11.06$ & 0.834 & $63.33 \pm 4.99$ & $91.5 \pm 7.69$ \\
\hline
\end{tabular}


Table 4. Reflects that there was a statistically significant improvement in the mean knee Function score and Lysholm knee score among the patients in study group post application of exercise program than the patients in the control group.
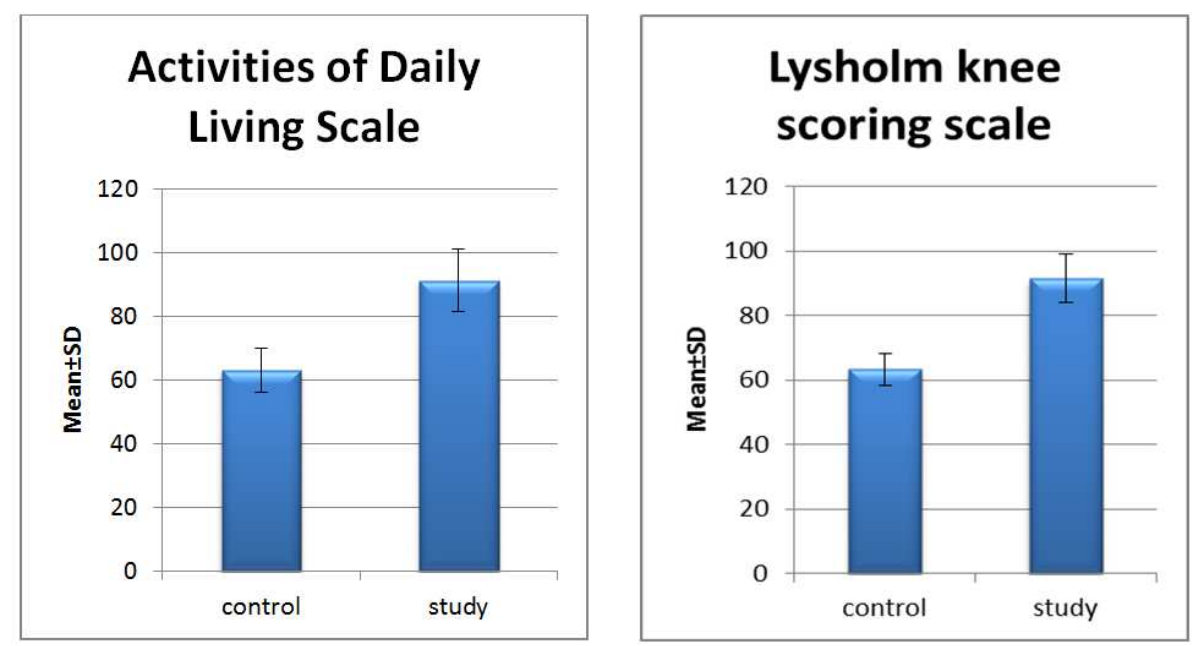

Figure 1. Mean and standard deviation of the study and control group regarding Activities of Daily Living Scale and Lysholm knee scoring scale four weeks after Application exercise program.

\section{Discussion}

High Tibia bone (HTO) has been developed as a contributing joint preserving surgery to treat young patients with medial or lateral isolation of arthritis in the knee and corresponding curvature or malalignment of the lower limb. Treatment was dispensed in patients with strong or minimal reduced knee mobility as non-operational interventions did not increase debilitating knee pain (Niinimak et al., 2012). [12]

Exercise following (HTO) could be a vital part of a full recovery, the physiotherapist must use their best clinical judgment into an appropriate treatment plan. Since a patient's progress is variable and each will have specific preoperative deficiencies, this exercise protocol has got to be individualized so on return optimally to preoperative status. During this procedure there could also be even minor differences if there are restrictions imposed by the surgery and therefore the condition of individuals recovering (Alderink et al, 2010) [13]

Part 1: Demographic data: There is agreement within the literature regarding the association between age and outcomes of HTO. Some Authors found that the risk of failure increased $7.6 \%$ for each year of age Trieb et al., (2006).

Regarding to age the result of present study showed that mean of patient age in study group was (42.53 \pm 9.44$)$, and $(43.73 \pm 10.42)$ in control group this result in agreement with Pannell et al., (2019) [14] found that mean age (43.93 \pm 9.49). In the same line Ihle et al., (2016) [15] reveal that mean age $(46 \pm 8)$ years. Also (van Egmond et al., (2016) [16] demonstrated that the mean age $(45 \pm 3.3)$ in their study. Bode et al., (2015) [17] and Trevor et al., (2009) [18] stated that mean age $(46.8 \pm 10.2)$ and $(47 \pm 4)$ years respectively, In another way this result contradicts the results by Niinimä et al., (2012) [12]. found that mean age of the participants was 54. Yokoyama et al., 2016) [19] most of patient were females; mean age 59.8 years).

In HTO opinion, it is increasingly used in young patients and physical activity with knee joint inflammation. Having strong expectations from these patients, including returning to sports by maintaining maternal knee structures, and returning to a very demanding athletic appears to be possible.

According to gender, the current study refers to, more than half of patients in the study group were females, more than half of patients were males in control group. Hoorntje et al. (2019). [20] in the same line who found in his study that most patient was female. Niinimäk et al., (2012). [12] expressed that approximately half of the operations were performed for female patients. Also Benzakour et al., (2010) [21] and Yokoyama et al., (2016) [19] stated that most of patient were females. This predominance of female subjects is explained by the link between knee osteoarthritis due to genu varum and obesity among women in our country.

As regard occupation and body mass index (BMI) more than two fifth of the studied patients were employed and more than half of the studied patients were obese. Close to result of present study Hoorntje et al., (2019). [20] and liu et al., (2019). [22] found that most of studied sample were employees. Given the worldwide increasing incidence of knee OA in working-age patients and employees patients indicated surgery for jobs that include knee-demanding activities, such as kneeling, lifting, and walking stairs Smith et al., (2013). [23]

The relationship between body mass index (BMI) and HTO results is still debatable within the literature by Flecher et al., (2006), who found that those who had a BMI of 30 but had better results. This finding was confirmed by Howells et al., (2014) who found that patients with a greater BMI of $10 \%$ above normal values had a pain-free period of 5 years versus 7.8 years for those with a BMI not reaching $10 \%$ 
above normal values. Since the normal values for BMI ranges between 18.5 and 24.9 , we are able to say that the largest BMI of 27.4 is related to the poorest outcomes. On the premise of the hypothesis that lighter patients are often more active, the Authors suggested that this finding may be associated with higher stress on the osteotomy site Bonasia et al., (2014). [24] concluded that in patients with a BMI greater than 30 the danger of unsuccessful surgery is 10 times higher, and Akizuki et al., (2008). [25] stated that a BMI greater than 27.5 is related to early failure of the osteotomy. we are able to conclude that the perfect BMI for HTO may be a value of between 25 and 27.5.

In the present study mean of BMI was $30.16 \pm 4.39$ in study group and $32.22 \pm 4.72$ in control group. In the same line Siboni etal, (2018). [26] found that Mean was $30.3 \pm 5.2 ; 17$, Hoorntje et al, (2019). [20]. and Ihle et al., (2016). [15] reveal BMI were 27.5 And $28.8 \pm 4$.7. respectively, also Yokoyama et al. (2016). [19] demonstrate BMI was $26.2 \pm$ 3.4. Briem \& Mackler., (2009). [27] Founded that BMI $\left(\mathrm{kg} / \mathrm{m}^{2}\right)$ 30.1 3.6, also Annette et al, (2009). [28] state that BMI 28.9.

Part II: Patients medical data: The results of the present study reveals that the highest percent of study group had high tibial osteotomy related to falling, The most affected side was the left side. In relation to type of operation, the highest percent of patients underwent lateral closing wedge osteotomy. In the same line Duivenvoorden et al., (2014) [29] and Harris et al., (2013) [30] who found that, closed wedge HTO performed most common respectively. Also, Hui et al., (2011) demonstrated that the main cause of surgery was posttraumatic.

While in the control group main causes of surgery were OA and pain, the affected side was the right side, medial open wedge osteotomy was performed. Ihle et al., (2016) [15], and van Egmond 1 et al., (2016). [16] demonstrated that most affected side is right leg respectively. In the same line Hoorntje et al., (2019). [20] who used Medial open wedge HTO and the indication for surgery was unicompartmental $\mathrm{OA}$ and varus or valgus knee alignment caused by a tibial deformity. Also Pannell et al., (2019). [14] founded in their study that most of patient have a diagnosis of OA. Martin et al., (2014) [31] Floerkemeier et al., (2013), [32] and Saragaglia et al., (2014) [33], prefer medial open wedge for their patients. Niinimäk et al., (2012) [12] state that the most common indication for osteotomy was primary OA.

No consensus on which is that the most effective osteotomy in terms of outcome because every kind have different indication. Conventional indications for OWHto are medial compartment osteoarthritis and varus malalignment of the knee. Recently WHto has been used successfully within the treatment of double and triple varus.

Sun, (2017) [34] for these reasons, interest during this procedure has grown in recent years Floerkemeier., et al (2013) [32] and Soleimanpour et al., (2013) [35] in their study showed statistically significant differences in operational time, weight bearing period and return to daily activities between oWHto and CWHto. Deie et al., (2014)
[36] Asserted that OWHto decreased varus moment and lateral thrustet while CWHto had no impact on lateral thrust reductions. other authors, like Duivenvoorden et al., (2014) [29] and Brouwer et al., (2006) [37] didn't find any differences.

Part IV: Patients' activity and environment: The present study illustrated that, quite three quarter of study patients were climb stairs up and down, while quite half of patients within the control group were carrying heavy objects and bending his knee. As regarding the residence level, about two fifth of patients within the study sample lived within the ground, while the majority within the control sample lived within the second and third level. Majority of patients in study and control using stairs to reach upper floors, while within the control group they were using squatting pan and this activity increase knee joint load. Within the identical line Jin et al., (2013) [38] revealed that the joint degeneration further lead to a varus deformity with increasing load transmission through the already degenerate compartment. Furthermore, knee joint loading are found to be altered in patients with early knee OA during gait. Kutzner et al., (2010) [39] added that knee joint could even be awfully complex and important joint for load and motion, including the tibio femoral joint and then the patella femoral joint. The steadiness of the joint especially knee hooked in to the interaction by ligamentous and cartilaginous structures, meniscus additionally as several muscles and tendons. Fraysse et al., (2016) [40] explained that the loads placed on the tibio femoral joint are more than a few times the load during everyday activities and the average peak resulting forces were the strongest during the descent of the stairs (346\% BW), followed by the ascending stairs (316\% BW) and the walking stage (261\% BW). Chen et al., (2014) [42] show that the medial-lateral force distribution relies on the tibio femoral alignment and varies within different weightbearing tasks. The medial-lateral load distribution on the tibia varies over a walking gait .And about $75 \%$ of the joint load goes through the medial tibial plateau during a single-leg position.

Tool II: knee Function: Knee Outcome Survey Activities of Daily Living Scale and Lysholm knee scale: The postoperative osteotomy exercise enables patients a minimum to deal better with daily activities. The world results attest a comparatively good initial outcome of knee function Benzakour et al., (2010) [21]

The current study illustrated that there was a statistically significant improvement within the mean knee function score in study group post application of exercise program than the patients within the control group. Da Cunha et al. (2019) [42] demonstrated that, improvement in functional outcome scores postoperative. Also, Van Egmond et al., (2016) [16] mention that a big improvement together clinical outcomes was also found and Lysholm knee score among the patients in study group post application of exercise program than the patients within the control group. In addition, Hoorntje et al., (2019) [20] founded that improvement after HTO within 
the mean Lysholm score at follow-up. Also lhle et al., (2016) [15] found improvement of the clinical conditions and, consequently, in patient daily working and recreational activities.

\section{Conclusion \& Recommendations}

The exercise program had a statistically significant effect on the improvement of physical function of knee among the study group than among the control group. Successful postoperative exercises should be practiced for each in order to improve the physical function of the knee.

\section{Acknowledgements}

We wish to express our sincere gratitude to all studied patients for cooperation throughout the study period. We also, extremely thankful and appreciating to nursing and medical staff of orthopedic surgery department and outpatient orthopedic clinic at Assiut University Hospital for their effort and cooperation.

\section{Disclosure}

The author reports no conflicts of interest in this work

\section{References}

[1] Shahcheraghi, G. H., Zarae, P., Javid, M. and Mahmoodian, B., (2007): High tibial valgus osteotomy and functional outcome. Iranian Journal of Medical Sciences, 32 (2), pp. 6673.

[2] Elson D., Paweleck J., Shields D., Dawson M., Ferrier G., (2013): Stretching the indications: high tibial osteotomy used successfully to treat isolated ankle symptoms. Case Reports, 2013, bcr2013200527.

[3] Niemeyer P., Schmal H., Hauschild O., von Heyden J., Südkamp N., Köstler W., (2010): Open-wedge osteotomy using an internal plate fixator in patients with medialcompartment gonarthritis and varus malalignment: 3-year results with regard to preoperative arthroscopic and radiographic findings. Arthroscopy. 26 (12): 1607-16.

[4] Amendola A, Bonasia DE, (2010): Results of high tibial osteotomy: review of the literature. Int Orthop. 2010; 34: 155160 .

[5] Savarese E., Bisicchia S., Romeo R., Amendola N., (2011): A. Role of high tibial osteotomy in chronic injuries of posterior cruciate ligament and posterolateral corner. J Orthop Traumatol. 12: 1-17.

[6] Asada S., Akagi M., Mori S., Matsushita T., Hashimoto K., Hamanishi C., (2012): Increase in posterior tibial slope would result in correction loss in frontal plane after medial openwedge high tibial osteotomy. Knee Surg Sports Traumatol Arthrosc. 2012; 20 (3): 571-8.

[7] Song E., Seon J., Park S., Jeong M., (2010): The complications of high tibial osteotomy: closing- versus opening-wedge methods. J Bone Joint Surg Br. 92: 1245-
1252.

[8] Frank R., Noyes D., Barber-W., (2017): In Noyes' Knee Disorders: Surgery, Rehabilitation, Clinical Outcomes (Second Edition).

[9] Rossi R., Bonasia D., Amendola A., (2011): The role of high tibial osteotomy in the varus knee. J Am Acad Orthop Surg. 19: 590-599.

[10] Irrgang J, Snyder-Mackler L, Wainner R, Fu F, Harner C., (1998) Development of a patient-reported measure of function of the knee. Journal of Bone Joint Surgery - American Volume 1998; 80-A (8): 1132-1145. Knee Outcome Survey Activities of Daily Living Scale (ADLS).

[11] Tegner Y, Lysholm J., (1985): Rating systems in the evaluation of knee ligament injuries. Clin Orthop Relat Res. 1985 Sep; (198): 43-9.

[12] Niinimak K., Eskelinen A., Mann B., Junnila M., Ohtonen P., Leppilahti J., (2012): Survivorship of high tibial osteotomy in the treatment of osteoarthritis of high-tibial osteotomy. Knee surg sports traumatol Arthrosc. 14: 149-152.

[13] Aalderink J., Shaffer M., Amendola A., (2010): Rehabilitation Following High Tibial Osteotomy. Clin Sports Med. 29: 291301.

[14] Pannell W., Heidari K., Mayer E., Zimmerman K., Heckmann N., McKnight B., Hill J., Vangsness C, Hatch G and Weber A (2019): High Tibial Osteotomy Survivorship, A Population-Based Study, The Orthopaedic Journal of Sports Medicine, 7 (12).

[15] Ihle C., Ateschrang A., Grünwald L., töckle U., Saier T and Schröter S., (2016): Health-related quality of life and clinical outcomes following medial open wedge high tibial osteotomy: a prospective study, Musculoskeletal Disorders 17: 215, DOI 10.1186/s12891-016-1076-x.

[16] Van Egmond N, Stolwijk N., Van Heerwaarden R., Van Kampen A., Keijsers N., (2016): Gait analysis before and after corrective osteotomy in patients with knee osteoarthritis and a valgus deformity, Knee Surg Sports Traumatol Arthrosc.

[17] Bode G., Heyden J., Pestka J., Schmal H., Salzmann G., Sudkamp N., Niemeyer P., (2015): Prospective 5-year survival rate data following open-wedge valgus high tibial osteotomy, Knee Surg Sports Traumatol Arthrosc 23: 1949-1955 DOI 10.1007/s00167-013-2762-y

[18] Trevor B., Giffin J., Bert M., Chesworth A., Dianne M., Robert B., Kevin W, Thomas R., and Peter J (2009): medial opening wedge high tibial osteotomy: a prospective cohort study of gait, radiographic, and patient-reported outcomes, Arthritis \& Rheumatism (arthritis care \& research), American College of Rheumatology, Vol. 61, No. 5, may 15, 2009, pp 648657.

[19] Yokoyama M., Nakamura Y., Onishi T, Hirano K., and Motoyuki D., (2016): Healing period after open high tibial osteotomy and related factors: Can we really say that it is long, Springer Plus.

[20] Hoorntje A., Paul F., Koen L., Rutger C., Gino M., and Ronald J. (2019): Prognostic Factors for Return to Sport After High Tibial Osteotomy Investigation performed at Sint Maartenskliniek Woerden, Woerden, the Netherlands, The American Journal of Sports Medicine, 47 (8): 1854-1862, DOI: $10.1177 / 0363546519849476$. 
[21] Benzakour T \& Hefti A \& Lemseffer M \& El Ahmadi J \& Bouyarmane H \& Benzakour A, (2010): High tibial osteotomy for medial osteoarthritis of the knee: 15 years follow-up, International Orthopaedics (SICOT) 34: 209-215

[22] Liu N., Agarwalla A. Garcia G., Christian D., Gowd A, Yanke A., Cole B., (2019): Return to Sport and Work After High Tibial Osteotomy With Concomitant Medial Meniscal Allograft Transplant, Arthroscopy: The Journal of Arthroscopic and Related Surgery, Vol -, No - (Month), 2019: pp 1-7.

[23] Smith O., Wilson A., Thomas P., (2013): Osteotomy around the knee: evolution, principles and results. Knee Surg Sports Traumatol Arthrosc. 2013; 21 (1): 3-22.

[24] Bonasia D., Dettoni F., Sito G., (2014): Medial opening wedge high tibial osteotomy for medial compartment overload/arthritis in the varus knee: prognostic factors. Am J sports Med. 42: 690-698.

[25] Akizuki S., shibakawa A., takizawa T., (2008): The long-term outcome of high tibial osteotomy: a ten- to 20 -year followup. J Bone Joint surg Br. 90: 592-596.

[26] Siboni R., Beaufils P., Boisrenoult P., Steltzlen C., Pujol N., (2018): pening-wedge high tibial osteotomy without bone grafting in severe varus osteoarthritic knee. Rate and risk factors of non-union in 41 cases, France Orthopaedics \& Traumatology: Surgery \& Research, 104 473-476.

[27] Briem, K., \& Snyder-Mackler, L. (2009). Proximal gait adaptations in medial knee OA. Journal of Orthopaedic Research, 27 (1), 78-83.

[28] Annette W., Larsen S., Roos E., (2009): Association between knee alignment and knee pain in patients surgically treated for medial knee osteoarthritis by high tibial osteotomy. A one year follow-up study, BMC Musculoskeletal Disorders, 10: 154 doi: $10.1186 / 1471-2474-10-154$

[29] Duivenvoorden T., Brouwer R., Baan A., (2014): Comparison of closing-wedge and opening-wedge high tibial osteotomy for medial compartment osteoarthritis of the knee: a randomized controlled trial with a six-year follow-up. J Bone Joint surg Am. 96: 1425-1432.

[30] Harris J., Mcneilan R., siston R., (2013): Survival and clinical outcome of isolated high tibial osteotomy and combined biological knee reconstruction. Knee.; 20: 154-161.

[31] Martin R., Birmingham B., Willits K., (2014): Adverse event rates and classifications in medial opening wedge high tibial osteotomy. Am J sports Med. 42: 1118-1126.

[32] Saragaglia D., Rouchy R., Krayan A., (2014): Return to sports after valgus osteotomy of the knee joint in patients with medial unicompartmental osteoarthritis. int orthop. 38: 21092114

[33] Sun H., Zhou L., Li F., Duan J. (2017): Comparison between closing-wedge and opening-wedge high tibial osteotomy in patients with medial knee osteoarthritis: a systematic review and meta-analysis. The Journal of Knee Surgery. 30 (2): 158 165. doi: 10.1055/s-0036-1584189.

[34] Floerkemeier S., staubli A., schroeter S., (2013): Outcome after high tibial open-wedge osteotomy: a retrospective evaluation of 533 patients. Knee surg sports traumatol Arthrosc. 21: 170-180.

[35] Soleimanpour J., Elmi A., Jafari MA., (2013): Comparison of Comparison of Genu Varum Treating Results Using Open and Closed Wedge High Tibial Osteotomy, Pakistan Journal of Biological Sciences 16 (14): 686-91.

[36] Deie M., Hoso T., shimada N., (2014): Differences between opening versus closing high tibial osteotomy on clinical outcomes and gait analysis. Knee. 21: 1046-1051.

[37] Brouwer R., Bierma M., van Raaij., (2006): osteotomy for medial compartment arthritis of the knee using a closing wedge or an opening wedge controlled by a Puddu plate. A one-year randomised, controlled study. J Bone Joint surg Br. 88: 1454-1459.

[38] Jin M., Holloway E., (2013): The young osteoarthritic knee: dilemmas in management. BMC Medicine. 2013; 11 (1): p. 14. doi: 10.1186/1741-7015-11-14.

[39] Kutzner I., Heinlein B., Graichen F., (2010): Loading of the knee joint during activities of daily living measured in vivo in five subjects. Journal of Biomechanics.; 43 (11): 2164-2173. doi: 10.1016/j. jbiomech. 03. 046.

[40] Erquicia J., Eduardo P., Perelli S., Ibañez F., Ibañez M., Pelfort X and Carlos J., (2019): Biplane opening wedge high tibial osteotomy with a distal tuberosity osteotomy, radiological and clinical analysis with minimum follow-up of 2 years, Journal of Experimental Orthopaedics, 10.1186/s40634-019-0176-6.

[41] Chen Z., Zhang X., Ardestani M., (2014): Prediction of in vivo joint mechanics of an artificial knee implant using rigid multi-body dynamics with elastic contacts. Proceedings of the Institution of Mechanical Engineers, Part H: Journal of Engineering in Medicine; 228 (6): 564-575. doi: 10.1177/0954411914537476.

[42] Da Cunha r., Kraszewski a., Hillstrom H., Fragomen A., Rozbruch S., (2019): Biomechanical and Functional Improvements Gained by Proximal Tibia Osteotomy Correction of Genu Varum in Patientswith Knee Pain, HSSJ Journal, DOI 10.1007/s11420-019-09670-6. 